\title{
Chloé Kattar, Saphir et Onyx
}

\section{Veronica Amadessi}

\section{(2) OpenEdition}

\section{Journals}

\section{Edizione digitale}

URL: http://journals.openedition.org/studifrancesi/7056

DOI: 10.4000/studifrancesi.7056

ISSN: 2427-5856

\section{Editore}

Rosenberg \& Sellier

\section{Edizione cartacea}

Data di pubblicazione: 1 septembre 2010

Paginazione: 415

ISSN: 0039-2944

\section{Notizia bibliografica digitale}

Veronica Amadessi, «Chloé Kattar, Saphir et Onyx», Studi Francesi [Online], 161 (LIV | II) | 2010, online dal 30 novembre 2015, consultato il 13 janvier 2021. URL: http://journals.openedition.org/ studifrancesi/7056 ; DOI: https://doi.org/10.4000/studifrancesi.7056

Questo documento è stato generato automaticamente il 13 janvier 2021.

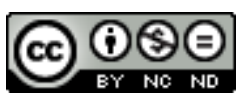

Studi Francesi è distribuita con Licenza Creative Commons Attribuzione - Non commerciale - Non opere derivate 4.0 Internazionale. 


\title{
Chloé Kattar, Saphir et Onyx
}

\author{
Veronica Amadessi
}

\section{NOTIZIA}

CHLOÉ KATTAR, Saphir et Onyx, Beyrouth, Dergham, 2009, pp. 119.

1 Con questa seconda raccolta di poesie (la prima era stata Or et Rubis, Beyrouth, Dergham, 2008, accolta con grande favore dalla critica al Salon francophone du livre de Beyrouth dello stesso anno), Chloé Kattar definisce con più chiarezza i tratti di una scrittura che si era già rivelata densa e matura. La giovanissima autrice libanese sottopone al lettore immagini ricche, con uno stile melodioso, ritmico e fresco, in cui la lingua francese occupa un ruolo di primo piano. La divisione del volume in due parti è netta, fin dal titolo stesso, che si compone di due elementi: lo zaffiro, pietra preziosa, inaugura la sezione dedicata alle poesie sul Libano e all'amore per questa terra, mentre l'onice, pietra il cui nome apre la seconda sezione, racchiude un gruppo di componimenti la cui materia è più eterogenea.

2 Se l'amore sembra essere un filo conduttore costante, altri sentimenti come il dolore, la disperazione, il dubbio affiorano nei versi di Chloé Kattar, lasciando intravedere l'allusione a personaggi mitologici, religiosi o letterari. Le due rive del Mediterraneo sono ben presenti nell'immaginario della scrittrice, che utilizza volentieri allegorie, metafore e allusioni per descrivere paesaggi a metà strada tra sogno e realtà. Il linguaggio è ricco, pieno di immagini, e fa emergere un'attenzione particolare per i metalli, le stoffe, le pietre, i materiali, come se il poeta fosse un artista alle prese con la materia. La preferenza accordata alle quartine non è assoluta, poiché alcuni passaggi assomigliano più a testi in prosa, il tutto presentato con un'eleganza sia stilistica che tipografica. La prosa poetica si alterna alle rime, così come la luce e l'ombra, i paesaggi libanesi e quelli europei si rincorrono dal primo all'ultimo testo. Alexandre Najjar ha detto di lei: «Ses poèmes sont pareils à un diamant brut que les années se chargeront de tailler et de polir. Le diamant brut a cela de magnifique qu'il est la promesse de la perfection». Tutte le recensioni della stampa libanese hanno scommesso sul successo di 
questa seconda raccolta e di quelle che seguiranno. Di certo si intravede la promessa di una poesia dalle mille sfaccettature, in cui il mélange di culture diverse arricchisce la lingua e le immagini descritte. 